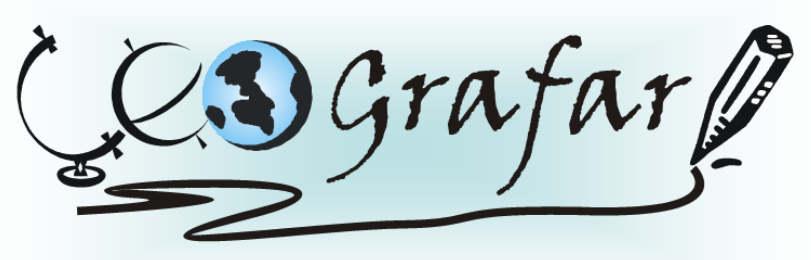

Revista Eletrônica do Programa de Pós-Graduação em Geografia - UFPR

\title{
GESTÃo DE RESÍDUOS SÓLIDOS URBANOS NA REGIÃO METROPOLITANA DE CURITIBA: POLÍTICA REGIONAL DE COMPOSTAGEM
}

\author{
PAULO NASCIMENTO NETO ${ }^{1}$ \\ TOMÁS ANTONIO MOREIRA ${ }^{2}$
}

\begin{abstract}
Resumo: A questão dos resíduos sólidos tem adquirido cada vez mais relevância nas discussões referentes ao planejamento urbano. E, na busca pela sustentabilidade ambiental as soluções contidas na esfera municipal perdem eficiência, visto que os sistemas ambientais sofrem degradações em extensões que extrapolam os limites do município. Neste sentido, destaca-se a figura do Consórcio Intermunicipal, integrando municípios vizinhos com problemas comuns, que reúnem esforços em busca de soluções. Acreditando neste pressuposto foi que em 2001, 17 municípios da Região Metropolitana de Curitiba (RMC) constituíram o Consórcio Intermunicipal Para Gestão de R.S.U.. Dentre as atividades do consórcio, está o Plano de Gerenciamento do Tratamento e Destinação de Resíduos Sólidos (PGRS), que propõe a substituição do atual Aterro Sanitário da Caximba por uma Planta de Tratamento, processando o lixo e aterrando apenas os rejeitos últimos. Porém, este novo sistema proposto não apresenta estratégias de implantação na prática. Neste sentido, este artigo propõe a elaboração de uma Política Regional de Compostagem, definindo diretrizes de planejamento territorial, de modo a viabilizar a prática da compostagem na RMC.
\end{abstract}

Palavras-chave: Compostagem; Região Metropolitana de Curitiba; Resíduos Sólidos.

\section{SOLID WASTE MANAGEMENT IN CURITIBA METROPOLITAN REGION: REGIONAL COMPOSTING POLICY}

\begin{abstract}
The issue of solid waste has become increasingly important in discussions relating to urban planning. And, in the search for sustainability, solutions in the municipal sphere lose efficiency, since the environmental systems suffer damage in extensions beyond the municipality limits. In this context, the Intermunicipal Consortium gains relevance, integrating neighboring cities with common problems, that congregate efforts in the search for solutions. Believing in this assumption, in 2001, 17 municipalities of the Curitiba Metropolitan Region constituted the Intermunicipal Consortium for Solid Waste Management. Among the activities of the consortium, there is the Treatment and Destination Management of Solid Waste Plan (PGRS), which proposes replacing the current landfill site (Caximba) for a waste treatment Plant, processing the trash and burying the final wasting. However, this proposed new system does not provide practical implement strategies. Therefore, this article proposes the establishment of a Composting Regional Policy, setting guidelines for territorial planning, in order to facilitate the practice of composting organic waste in the Curitiba Metropolitan Region.
\end{abstract}

Key words: Composting; Curitiba Metropolitan Region; Solid waste.

\footnotetext{
${ }^{1}$ Graduado em Arquitetura e Urbanismo pela PUCPR (2008), Mestrando em Gestão Urbana - orientação Projeto e Planejamento em Espaços Urbanos e Regionais pela PUCPR. Desenvolve trabalhos na área de Planejamento Urbano, com foco na Elaboração de Planos Diretores Municipais. paulo.nn@uol.com.br

${ }^{2}$ Graduado em Arquitetura e Urbanismo pela PUC Campinas (1988); Mestre em Ciências Aplicadas orientação Habitat \& Desenvolvimento pela Université Catholique de Louvain, Louvain-la-Neuve - Bélgica (1996); Ph.D. em Estudos Urbanos pela Université du Québec à Montréal, Montreal - Canadá (2006). e professor do Programa de Pós-Graduação em Gestão Urbana - PPGTU e do Curso de Arquitetura e Urbanismo PUCPR. tomas.moreira@pucpr.br
} 


\section{PANORAMA GLOBAL}

A questão dos resíduos sólidos tem adquirido cada vez mais relevância nas discussões referentes a territórios metropolitanos e ao seu planejamento urbano. Segundo MENEZES (2005), O acelerado processo de urbanização, aliado ao consumo crescente de produtos não duráveis, provocou um salto no volume de resíduos gerado, cujo crescimento foi três vezes maior que o populacional nos últimos 30 anos.

Em 1950, a geração mundial de lixo era de $0,5 \mathrm{~kg} / \mathrm{hab}$ dia. Cinqüenta anos depois, em 2000, esse índice já alcança 2 kg/hab dia nos países desenvolvidos. Este salto na geração de resíduos sólidos urbanos está intimamente relacionado aos hábitos de consumo. No Brasil, a média per capita ainda gira em torno de 0,7 kg/hab dia, mas pode alcançar $2,0 \mathrm{~kg} / \mathrm{hab}$. dia em áreas fortemente urbanizadas, como São Paulo (JARDIM, 2000).

Tal realidade fica clara quando observados os dados da Pesquisa Nacional de Saneamento Básico (PNSB) realizado pelo IBGE (2000), onde apenas 10\% (524) dos municípios brasileiros com mais de 50 mil habitantes geram $80 \%$ de todo o lixo coletado no país, sendo que as 13 maiores cidades brasileiras, são responsáveis por $32 \%$ de todo o lixo urbano coletado.

Além do aumento do volume gerado, o processo de urbanização também altera a composição dos resíduos sólidos. A produção elevada de papel na Europa, por exemplo, deve-se ao alto grau de industrialização e aos bens de consumo descartáveis produzidos e amplamente utilizados pela maioria da população. Para os países em desenvolvimento, como no caso do Brasil, a geração de resíduo ainda é, em sua maioria, de procedência orgânica, como pode ser visto no gráfico abaixo.

Na busca por uma solução viável, o Desenvolvimento Sustentável adquire importância fundamental. O termo, utilizado pela ONU no Relatório de Brundtland (1987), surge junto com as intensas discussões sobre o excessivo crescimento demográfico, sobretudo nos espaços urbanos metropolitanos, orientado em um modelo de desenvolvimento baseado no consumo de bens naturais. Neste cenário, ele adquire como função "compatibilizar o ganho econômico, a distribuição dos bens e a proteção da natureza" (IPARDES, 2006). Assim, o grau de sustentabilidade pode 
ser mensurado pela capacidade da sociedade utilizar os recursos naturais de modo equilibrado, garantindo o sustento das gerações atuais e futuras.
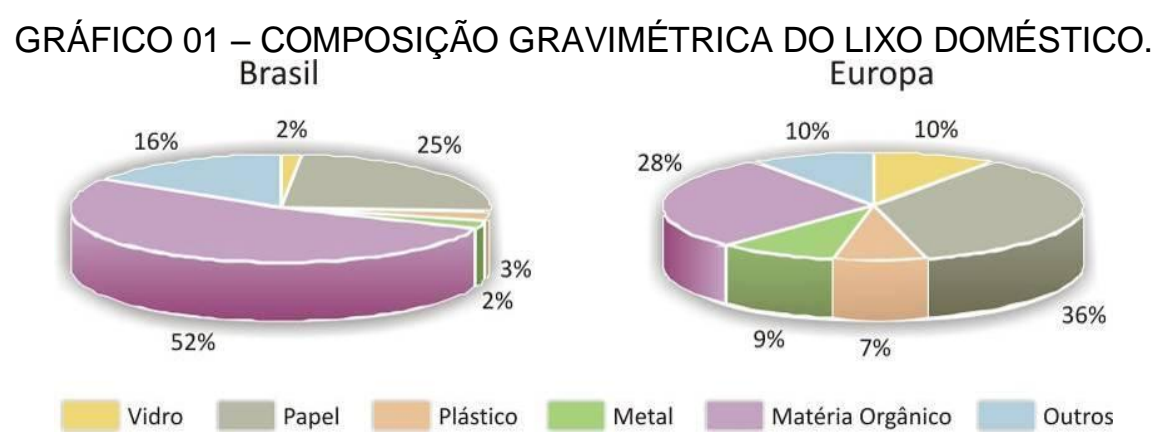

Fonte: Autor baseado em JARDIM, 2000.

Esta idéia também é adotada por ROGERS (2001), que defende a cidade de Metabolismo Circular, que minimiza novas entradas de energia e maximiza a reciclagem. O autor propõe a ordenação territorial dentro de um esquema policêntrico, onde se formam diversos centros de atividades sociais, econômicas e institucionais que polarizam a população do entorno. A teoria desenvolvida por ROGERS (2001) pode ser estendida a planos de análise ampliados, onde a organização espacial de um território, a partir de diversos núcleos devidamente interligados, geraria a maximização da eficiência energética, reduziria custos e fluxos de transporte e conseqüentemente a emissão de poluentes no meio ambiente.

\section{A REGIÃO METROPOLITANA DE CURITIBA}

Criada em 1973, a Região Metropolitana de Curitiba (RMC) ocupa uma área de $15.461 \mathrm{Km}^{2}$ e atualmente é composta de 26 municípios. Estes, somados, concentram 28,95\% da população do estado do Paraná, totalizando 2.768 .394 habitantes, segundo o Censo Demográfico (IBGE, 2000).

Situada no entroncamento viário entre a BR-116 (que conecta o sudeste ao sul do país) e a BR-277 (que liga o interior do Estado ao porto de Paranaguá), teve sua consolidação como metrópole regional na década de 1970, quando recebeu significativo fluxo migratório vindo do interior do Estado. 
Com a inserção de um contingente populacional significativo, o território urbano de Curitiba, capital do Estado e pólo regional, extrapolou seus limites administrativos e estendeu-se, formando uma mancha urbana contínua que agrega atualmente 14 municípios. Esta área conurbada, denominada de Núcleo Urbano Central (NUC), "concentra $97,73 \%$ da população urbana da Região Metropolitana, sendo uma área de alta complexidade e rápidas transformações urbanas, com impactos negativos ao meio ambiente" (COMEC, 2006).

A partir do momento que os sistemas ambientais sofrem degradação em extensões que extrapolam os limites municipais, obtém fundamental importância a integração da Ação Política com o Planejamento Regional, estabelecendo mecanismos de efetiva colaboração entre os municípios que compartilham da mesma problemática.

Neste sentido, destaca-se a figura do Consórcio Intermunicipal $(\mathrm{Cl})$, que busca "solucionar problemas comuns, que atingem municípios vizinhos, no qual cada ente consorciado disponibiliza os recursos financeiros e humanos que possui para concretizar as ações a serem realizadas pelo Cl” (OLIVEIRA, 2004). Acreditando neste pressuposto foi que em 2001, 17 municípios da Região Metropolitana de Curitiba constituíram o Consórcio Intermunicipal Para Gestão de Resíduos Sólidos Urbanos, tendo por objetivo organizar as ações e atividades relacionadas ao Sistema de Tratamento e Destinação Final dos resíduos sólidos urbanos gerados. Os municípios integrantes, bem como sua inserção dentro dos limites territoriais da RMC podem ser visualizados na figura 01 .

Entre as atividades desenvolvidas pelo Consórcio foi elaborado, em 2007, o Plano de Gerenciamento do Tratamento e Destinação de Resíduos Sólidos (PGRS). O escopo deste Plano é "o tratamento e a destinação final do lixo proveniente da coleta domiciliar, de varrição e limpeza dos logradouros públicos, realizadas de forma direta ou indireta pelos municípios que integram o Consórcio, sendo encaminhados para o Sistema Integrado de Processamento e Aproveitamento de Resíduos - SIPAR" (CONRESOL, 2007). 


\section{FIGURA 01 - ÁREA DE ABRANGÊNCIA DO CONSÓRCIO INTERMUNICIPAL PARA GESTÃO DE} R.S.U.

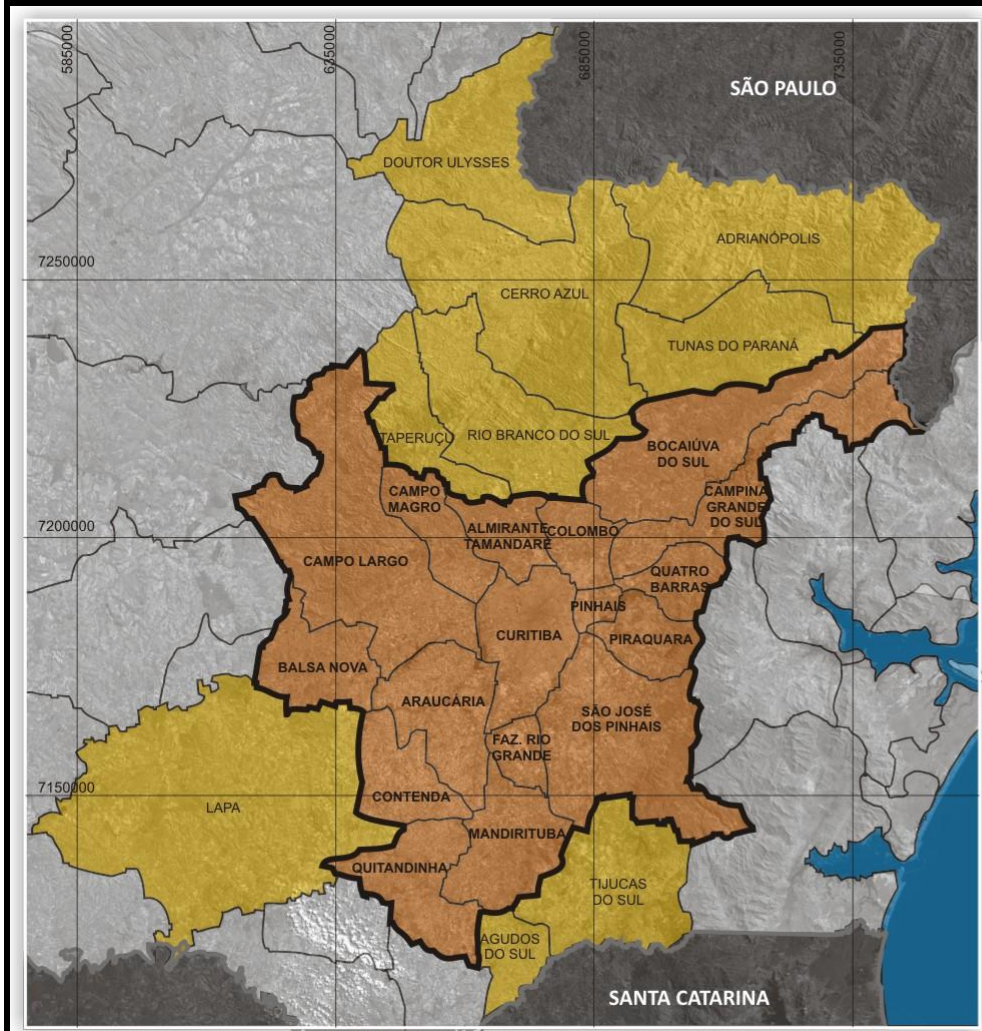

INSERÇÃO DO CONRESOL NA REGIÃO METROPOLITANA DE CURITIBA

Escala gráfica

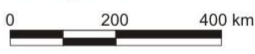

Legenda

Área de Intervenção

Região Metropolitana de Curitiba

Fonte: Autor, baseado em CONRESOL (2007).

Apesar de abranger o sistema como um todo, o escopo principal do PGRS trata da substituição do Aterro da Caximba, destinação atual dos resíduos sólidos dos municípios consorciados (exceto Balsa Nova e Quitandinha). Localizado no extremo sul de Curitiba, o Aterro teve seu esgotamento decretado em 2002, após receber mais de 11 milhões de toneladas de resíduos (3,4 vezes a capacidade inicial). Porém, a falta de uma solução viável vem forçando as autoridades a mantê-lo em funcionamento. 


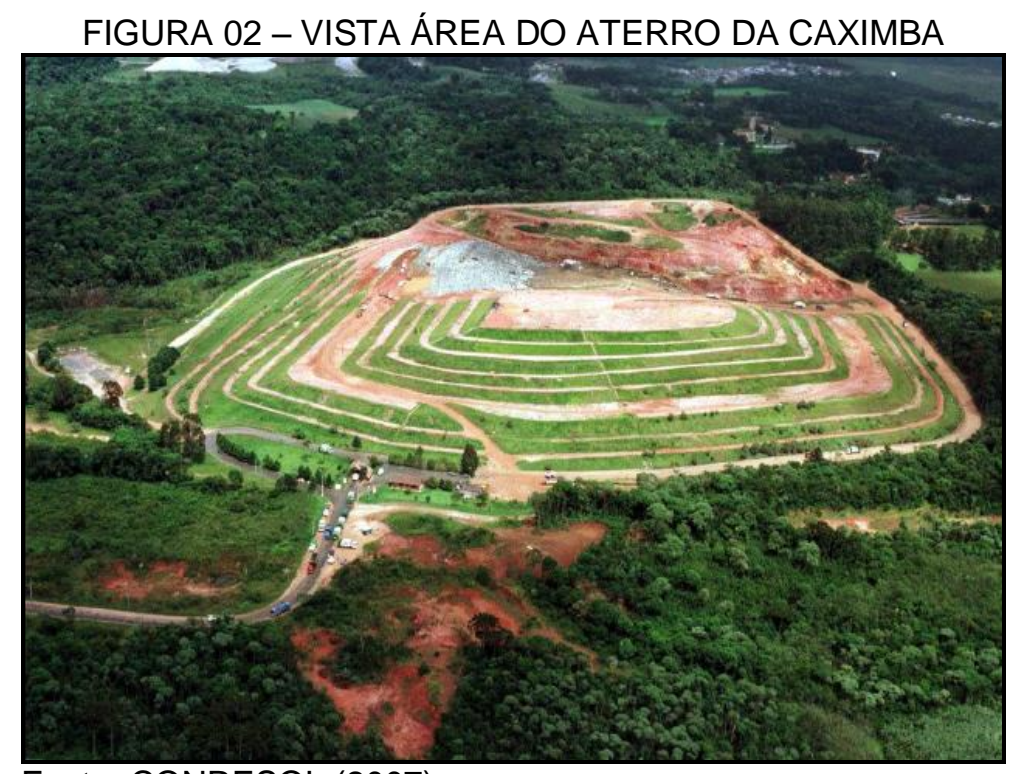

Fonte: CONRESOL (2007).

O Sistema proposto não concentra suas ações apenas na substituição do sítio para o aterramento dos resíduos, englobando também o processamento dos mesmos, maximizando a reciclagem e a compostagem, conseqüentemente minimizando o volume aterrado. Neste sentido, foram concebidas metas, a serem alcançadas progressivamente, até o momento em que não seja mais admitido lixo bruto no Aterro Sanitário. Tais metas são apresentadas podem ser observadas no quadro 01.

QUADRO 01 - METAS PARA TRATAMENTO DOS RESÍDUOS NO SIPAR

\begin{tabular}{|c|c|c|c|c|c|}
\hline $\begin{array}{l}\text { Período } \\
\text { (ano) }\end{array}$ & $\begin{array}{l}\text { Quantidade de } \\
\text { resíduos } \\
\text { processadas }\end{array}$ & $\begin{array}{l}\text { Bruto } \\
\text { tido no } \\
\text { erro }\end{array}$ & $\begin{array}{r}\text { Quantidade } \\
\text { Rejeito do Pr } \\
\text { destinado }\end{array}$ & $\begin{array}{l}\text { máxima de } \\
\text { ocessamento } \\
\text { ao Aterro }\end{array}$ & $\begin{array}{c}\text { Resíduos } \\
\text { admitidos no } \\
\text { Aterro Sanitário }\end{array}$ \\
\hline $1^{\circ}$ ao $3^{\circ}$ & $60 \%$ & $40 \%$ & & $20 \%$ (de $60 \%$ ) & $52 \%$ \\
\hline 4 ao $5^{\circ}$ & $80 \%$ & $20 \%$ & & $20 \%$ (de $80 \%$ ) & $36 \%$ \\
\hline $6^{\circ}$ ano - & $100 \%$ & 0 & & $15 \%$ & $15 \%$ \\
\hline $\begin{array}{l}\text { Período } \\
\text { (ano) }\end{array}$ & $\begin{array}{c}\text { Separação de Recicláveis } \\
\text { na Planta }\end{array}$ & $\begin{array}{r}\mathrm{Pr} \\
\text { Comp }\end{array}$ & $\begin{array}{l}\text { odução de } \\
\text { osto Orgânico }\end{array}$ & \multicolumn{2}{|c|}{$\begin{array}{l}\text { Outras formas de } \\
\text { Aproveitamento }\end{array}$} \\
\hline 1ㅇ ao $3^{\circ}$ & \multicolumn{2}{|l|}{$10 \%$ de $60 \%$} & \multicolumn{2}{|l|}{$5 \%$ de $60 \%$} & (85\% de $60 \%)$ \\
\hline 4 ao $5^{\circ}$ & \multicolumn{2}{|l|}{$10 \%$ de $80 \%$} & \multicolumn{2}{|l|}{$10 \%$ de $80 \%$} & $(80 \%$ dos $80 \%)$ \\
\hline $6^{\circ}$ ano - & \multicolumn{2}{|l|}{$10 \%$ de $100 \%$} & $15 \%$ de $100 \%$ & & (75\% dos $100 \%)$ \\
\hline
\end{tabular}

Fonte: CONRESOL, 2007.

Embora a adoção do novo sistema seja proposta, não são indicadas estratégias de aplicação do Plano na prática. Neste sentido, propõe-se a elaboração 
de uma Política Regional de Compostagem, definindo diretrizes de planejamento territorial, de modo a viabilizar a prática da compostagem na RMC.

\section{MUNICÍPIOS DO CONSÓRCIO INTERMUNICIPAL PARA GESTÃO DE R.S.U.}

\section{Macro-caracterização Sócio-econômica}

Os 17 municípios integrantes do consórcio perfazem área igual a 7.224 km², abrangendo basicamente o chamando Núcleo Urbano Central (NUC), com exceção apenas de Balsa Nova, Bocaiúva do Sul, Contenda, Mandirituba e Quitandinha.

Esta classificação, realizada pela COMEC, parte das relações entre os municípios integrantes da divisão política da RMC. Assim, o NUC reúne Curitiba e as porções urbanizadas de seus vizinhos, onde realmente se concentra a dinâmica metropolitana. Neste recorte é que são percebidos os processos de conurbação, movimento pendular e interdependência econômica.

Tanto na análise dos aspectos sociais como econômicos, pode-se perceber o mesmo panorama. A mancha urbana do NUC concentra mais de $93 \%$ da população da Área de Intervenção, de um total de 2.452.859 habitantes.

No que diz respeito ao PIB municipal, a distribuição apresenta concentração no pólo ( $51 \%$ do total da área de intervenção) e em outros dois municípios: Araucária e São José dos Pinhais, cada um com 16\% de participação. Com menor intensidade, mas ainda relevante, ressalta-se Balsa Nova e Quatro Barras, com PIB per capita elevado. Mas segundo MOURA (2006), a presença de uma grande empresa industrial em municípios com contingente populacional reduzido interfere fortemente neste dado.

Destaca-se ainda o caso de Mandirituba, que apresenta PIB per capita próximo ao de Curitiba, mas cuja atividade principal baseia-se na agroindústria. Quanto aos menores valores, pode-se citar Piraquara - área de preservação de mananciais de abastecimento de água para toda a Região e com sérias restrições de implantação de atividades econômicas em seu território - e Quitandinha, cujo principal componente na formação do PIB é a atividade agropecuária de pequena escala. 


\section{Macro-caracterização Ambiental}

$\mathrm{Na}$ análise de aglomerados metropolitanos, uma das questões ambientais que ganha grande notoriedade é a gestão dos recursos hídricos, sobretudo dos Mananciais de Abastecimento de Água. Ao se trabalhar com resíduos sólidos, correse o risco de haver sua dispersão nestas áreas, com conseqüente carreamento para o leito dos rios resultando em complexos impasses para a manutenção da qualidade das águas. Também se destaca a infiltração no solo, comprometendo lençóis freáticos. Na RMC, as Áreas de Mananciais são regidas pelo Decreto Estadual no. 6390/06, e estão presentes em todos os municípios do recorte de análise, exceto Curitiba. É relevante ainda destacar o Aqüífero $\mathrm{Karst}^{3}$, por suas características particulares.

Sob os aspectos geológicos, o Recorte de Análise possui composição variada, apresentando diversos compartimentos em seu território. Em cada compartimento ocorre uma paisagem distinta. Deste aspecto, uma das informações de grande importância do meio físico para este tema se concentra na localização das planícies aluviais. Segundo COMEC (2006) estas áreas são indicadas à preservação, em função "das características inadequadas para ocupação, associadas ao risco de ocorrência de cheias periódicas e da grande importância para a manutenção do equilíbrio hidrológico".

Outro dado de fundamental importância é o mapeamento das declividades, que auxilia na compreensão do território, sendo possível perceber as áreas que apresentam acidentes geográficos de grande relevância, influenciando na questão de acessibilidade regional. As porções do território com declividades elevadas se localizam predominantemente no setor Norte da Área de Intervenção, sendo ainda relevante uma pequena porção nos municípios de Mandirituba e São José dos Pinhais.

\footnotetext{
${ }^{3}$ Segundo COMEC (2006), "apresenta, do ponto de vista geotécnico, condições altamente instáveis no substrato rochoso com alta vulnerabilidade à contaminação das águas subterrâneas. A presença de cavernas de dissolução nas rochas calcáreas implica em risco geológico de colapsos e afundamentos, de ocorrência natural mas que podem ser induzidos pela ação humana". No recorte de Análise, o relevo cárstico se faz presente em diversos municípios, quais sejam: Almirante Tamandaré, Campo Magro, Colombo, Bocaiúva do Sul e Rio Branco do Sul.
} 


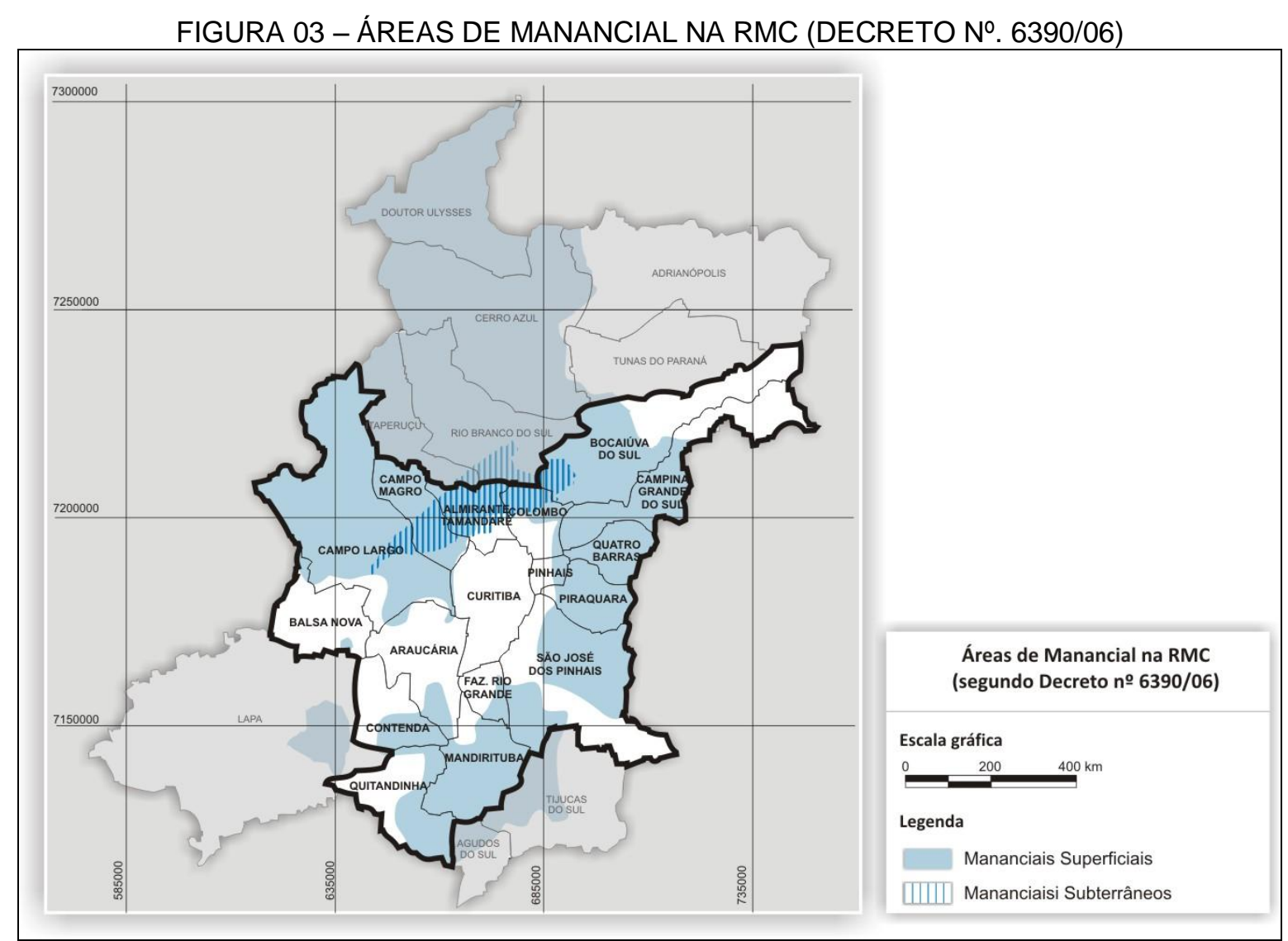

Fonte: Autor, baseado em COMEC (2006).

Quanto aos remanescentes florestais, um mapeamento recente é o realizado pelo SOS Mata Atlântica, disponível em COMEC (2006). Através da sua interpretação, é possível identificar os locais com maior incidência de vegetação nativa. Percebe-se que estes se mantêm mais conservados, em grandes extensões, justamente nas porções onde não se verificam manchas urbanas (Serra do Mar e Noroeste da Área de Intervenção). Ainda vale destacar que o Recorte de Análise é atingido por 20 das 21 Unidades de Conservação (UC's) da RMC, abrangendo tanto Áreas de Proteção Integral como Áreas de Uso Sustentável. 


\section{Macro-caracterização de Mobilidade Regional}

O sistema rodoviário da Área de Intervenção é estruturado por inúmeras rodovias, dentre elas se destacam como principais eixos viários as rodovias federais BR-116, BR-476 e BR-277, que condicionam o principal eixo de escoamento de produção da região.

Quanto ao restante da malha viária, segundo IPARDES (2004), ainda que todos os municípios sejam atendidos por estradas pavimentadas, há presença de trechos sem conservação distribuídos nas áreas periféricas.

Para este trabalho, julgou-se conveniente utilizar a metodologia adotada no PDI - RMC 2006, que analisou o grau de acessibilidade dentro do território. Entendendose por acessibilidade urbana, a função exercida pelo sistema viário como estrutura condutora das viagens geradas pelos deslocamentos de passageiros e de cargas dentro do espaço urbano.

Segundo COMEC (2006), "adotou-se como variáveis indicativas de acessibilidade: a distância de determinado ponto (ponto qualquer) ao centro da metrópole, e a distância desse ponto a uma via pertencente ao sistema viário metropolitano. Dessa forma, definiu-se que o fator de acessibilidade de determinada área fosse representado pela multiplicação do inverso dessas duas distâncias entre si, o que permite estabelecer que o afastamento do centro da metrópole ou de alguma via de importância metropolitana, determina a diminuição do grau de acessibilidade de uma área". Partindo desta metodologia, foi obtido o mapa a seguir, que apresenta os diferentes níveis de acessibilidade referentes aos deslocamentos de passageiros e cargas na mancha urbana da área de intervenção. 


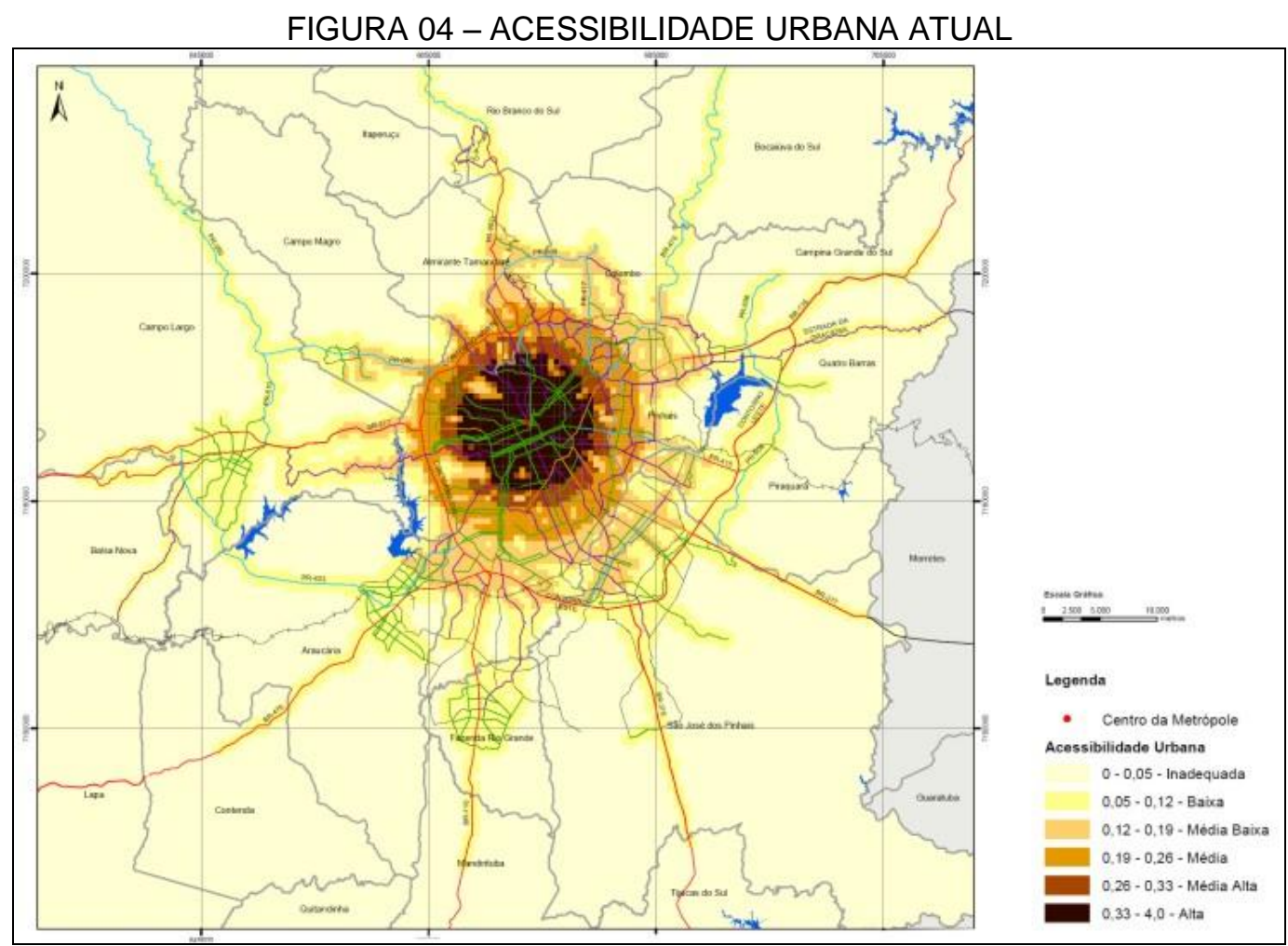

Fonte: COMEC, 2006

\section{Macro-caracterização do Sistema Atual de Gestão dos Resíduos Sólidos}

De modo a realizar uma caracterização geral do sistema, optou-se por abordar os principais aspectos relacionados às três etapas básicas de gerenciamento de resíduos sólidos: (1) coleta, (2) tratamento e (3) destinação final. A figura 05 apresenta a síntese destes aspectos, relacionando-os com as ações previstas no PGRS. Como pode ser visto, o grande desafio consiste em viabilizar um Programa Metropolitano de Compostagem, de modo a dar nova função aos resíduos orgânicos que, atualmente, somente contribuem na redução da vida útil do Aterro Sanitário. 


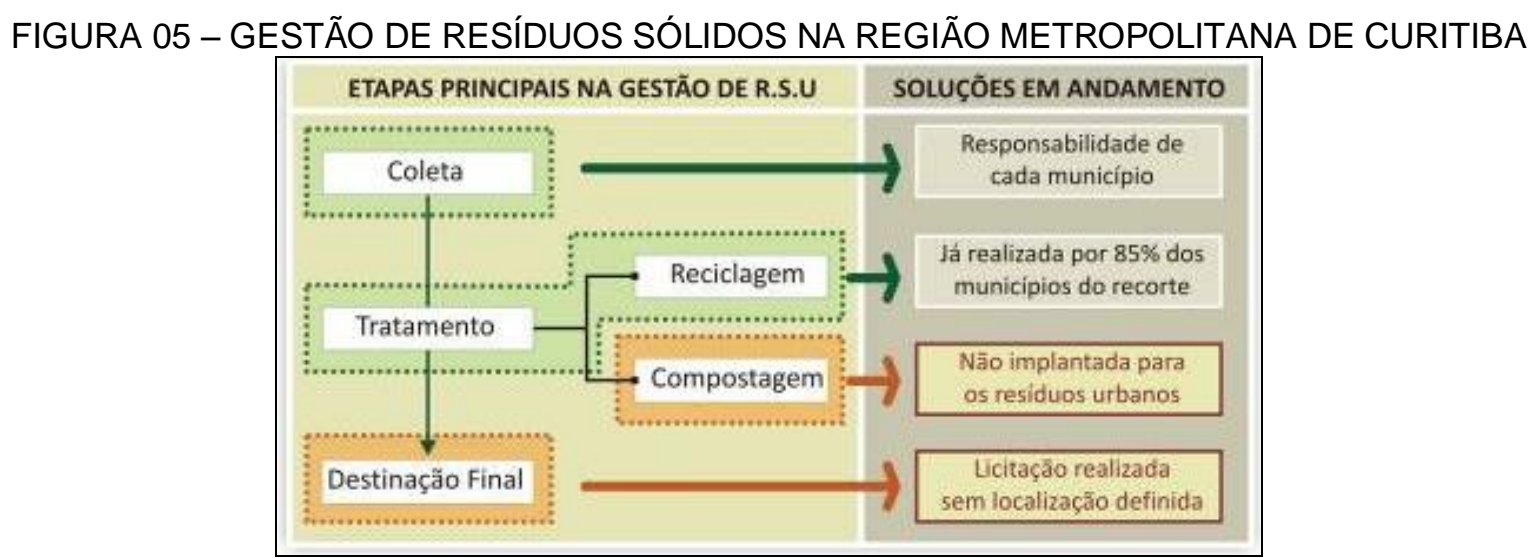

Fonte: Autor.

Quanto à Coleta, a população residente na área urbana é atendida quase em sua totalidade nos municípios da Área de Intervenção. Já as condições de coleta na zona rural variam significativamente em cada município, oscilando de $30 \%$ até $100 \%$ de atendimento. A questão da coleta não foi contemplada no PGRS, sendo de responsabilidade de cada municipalidade que, via de regra, vem terceirizando 0 serviço.

QUADRO 02 - ABRANGÊNCIA DA COLETA NA ÁREA DE INTERVENÇÃO

\begin{tabular}{|c|c|c|c|c|c|}
\hline Município & $\begin{array}{c}\text { Área Urbana } \\
(\%)\end{array}$ & $\begin{array}{l}\text { Área Rural } \\
\text { (\%) }\end{array}$ & Município & $\begin{array}{c}\text { Área Urbana } \\
\text { (\%) }\end{array}$ & $\begin{array}{c}\text { Área } \\
\text { Rural } \\
(\%)\end{array}$ \\
\hline Alm.Tamandaré & 95 & 51 & Curitiba & 100 & - \\
\hline Araucária & 100 & 100 & Faz. Rio Grande & 95 & 70 \\
\hline Balsa Nova & 100 & 60 & Mandirituba & 100 & 30 \\
\hline Bocaiúva do Sul & 100 & 30 & Pinhais & 100 & - \\
\hline C. G. do Sul & 100 & sem dado & Piraquara & sem dado & sem \\
\hline Campo Largo & 100 & 25 & & & dado \\
\hline Campo Magro & 100 & 40 & Quatro Barras & 100 & 20 \\
\hline Colombo & 97 & 97 & Quitandinha & 95 & 35 \\
\hline Contenda & 100 & 85 & S. J. dos Pinhais & 100 & 100 \\
\hline
\end{tabular}

Fonte:CONRESOL, 2007

A segregação dos resíduos recicláveis já vem sendo praticada em $85 \%$ dos municípios integrantes da área de Intervenção. Apenas Bocaiúva do Sul, Colombo e Pinhais não dispõem de programa de coleta seletiva. Já a compostagem dos resíduos orgânicos é verificada apenas em Campo Largo e Curitiba, e relaciona-se 
somente com os resíduos vegetais (folhas, restos de podas e congêneres). Como afirmado anteriormente, a principal questão abordada no PGRS é a substituição do Aterro da Caximba, destinação atual de todos os municípios do recorte exceto Balsa Nova e Quitandinha. O quadro 03 apresenta a descriminação das diferentes destinações dos resíduos por município.

QUADRO 03 - DESTINAÇÃO DOS DIFERENTES RESÍDUOS NA ÁREA DE INTERVENÇÃO

\begin{tabular}{|c|c|c|c|}
\hline Município & Domiciliar & Reciclável & Vegetais \\
\hline $\begin{array}{l}\text { Almirante } \\
\text { Tamandaré }\end{array}$ & $\begin{array}{l}\text { Aterro Sanitário de } \\
\text { Curitiba }\end{array}$ & $\begin{array}{l}\text { Associação de Catadores } \\
\text { ASSOL }\end{array}$ & Fonte energética \\
\hline Araucária & $\begin{array}{c}\text { Aterro Sanitário de } \\
\text { Curitiba }\end{array}$ & $\begin{array}{c}\text { Associação de Catadores } \\
\text { RECICLAR e CMPR da } \\
\text { SMMA }\end{array}$ & Disposição em terreno \\
\hline Balsa Nova & Aterro Próprio & $\begin{array}{c}\text { Barracão de Reciclagem } \\
\text { Municipal }\end{array}$ & Disposição em terreno \\
\hline Bocaiúva do Sul & $\begin{array}{l}\text { Aterro Sanitário de } \\
\text { Curitiba }\end{array}$ & $\begin{array}{l}\text { Comercialização pela } \\
\text { empresa responsável pela } \\
\text { coleta }\end{array}$ & Aterro Sanitário de Curitiba \\
\hline $\begin{array}{l}\text { Campina } \\
\text { Grande do Sul }\end{array}$ & $\begin{array}{c}\text { Aterro Sanitário de } \\
\text { Curitiba }\end{array}$ & $\begin{array}{l}\text { Material doado para } \\
\text { depósitos }\end{array}$ & Pátio da Prefeitura \\
\hline Campo Largo & $\begin{array}{l}\text { Aterro Sanitário de } \\
\text { Curitiba }\end{array}$ & Barracão de Triagem & $\begin{array}{l}\text { Compostagem do Fino e } \\
\text { Armazenamento do Lenhoso }\end{array}$ \\
\hline Campo Magro & $\begin{array}{l}\text { Aterro Sanitário de } \\
\text { Curitiba }\end{array}$ & $\begin{array}{l}\text { Unidade de Valorização de } \\
\text { Materiais Recicláveis }\end{array}$ & Disposição em Área rural \\
\hline Colombo & $\begin{array}{l}\text { Aterro Sanitário de } \\
\text { Curitiba }\end{array}$ & PET SUL Rede Solidária & Aterro Sanitário de Curitiba \\
\hline Contenda & $\begin{array}{l}\text { Aterro Sanitário de } \\
\text { Curitiba }\end{array}$ & Venda para terceiros & $\begin{array}{l}\text { Trituração e Fonte } \\
\text { Energética }\end{array}$ \\
\hline Curitiba & $\begin{array}{c}\text { Aterro Sanitário de } \\
\text { Curitiba }\end{array}$ & $\begin{array}{l}\text { Unidade de valorização de } \\
\text { materiais recicláveis }\end{array}$ & $\begin{array}{l}\text { Unidade de Processamento } \\
\text { de Resíduos Vegetais }\end{array}$ \\
\hline $\begin{array}{l}\text { Fazenda Rio } \\
\text { Grande }\end{array}$ & $\begin{array}{l}\text { Aterro Sanitário de } \\
\text { Curitiba }\end{array}$ & - & Aterro Sanitário de Curitiba \\
\hline Mandirituba & $\begin{array}{c}\text { Aterro Sanitário de } \\
\text { Curitiba }\end{array}$ & $\begin{array}{l}\text { Comitê contra fome e pela } \\
\text { moradia }\end{array}$ & Disposição em Área rural \\
\hline Pinhais & $\begin{array}{c}\text { Aterro Sanitário de } \\
\text { Curitiba }\end{array}$ & $\begin{array}{l}\text { Encaminhado para } \\
\text { reciclagem pela empresa } \\
\text { coletora }\end{array}$ & Horto municipal \\
\hline Piraquara & $\begin{array}{c}\text { Aterro Sanitário de } \\
\text { Curitiba }\end{array}$ & , & \\
\hline Quatro Barras & $\begin{array}{l}\text { Aterro Sanitário de } \\
\text { Curitiba }\end{array}$ & $\begin{array}{c}\text { Empresas recicladoras no } \\
\text { município }\end{array}$ & Horto municipal \\
\hline Quitandinha & Lixão Municipal & Centro de Triagem & Lixão municipal \\
\hline $\begin{array}{l}\text { São José dos } \\
\text { Pinhais }\end{array}$ & $\begin{array}{l}\text { Aterro Sanitário de } \\
\text { Curitiba }\end{array}$ & Usina da APMI & Tibagi Sistemas Ambientais \\
\hline
\end{tabular}

Fonte: CONRESOL, 2007 
Observando-se a composição gravimétrica dos resíduos recebidos no Aterro Sanitário da Caximba (atual destinação final), pode-se perceber que a matéria orgânica representa forte componente. Segundo dados do CONRESOL (2007), atualmente a quantidade de resíduos com potencial compostável supera 850 ton/dia.

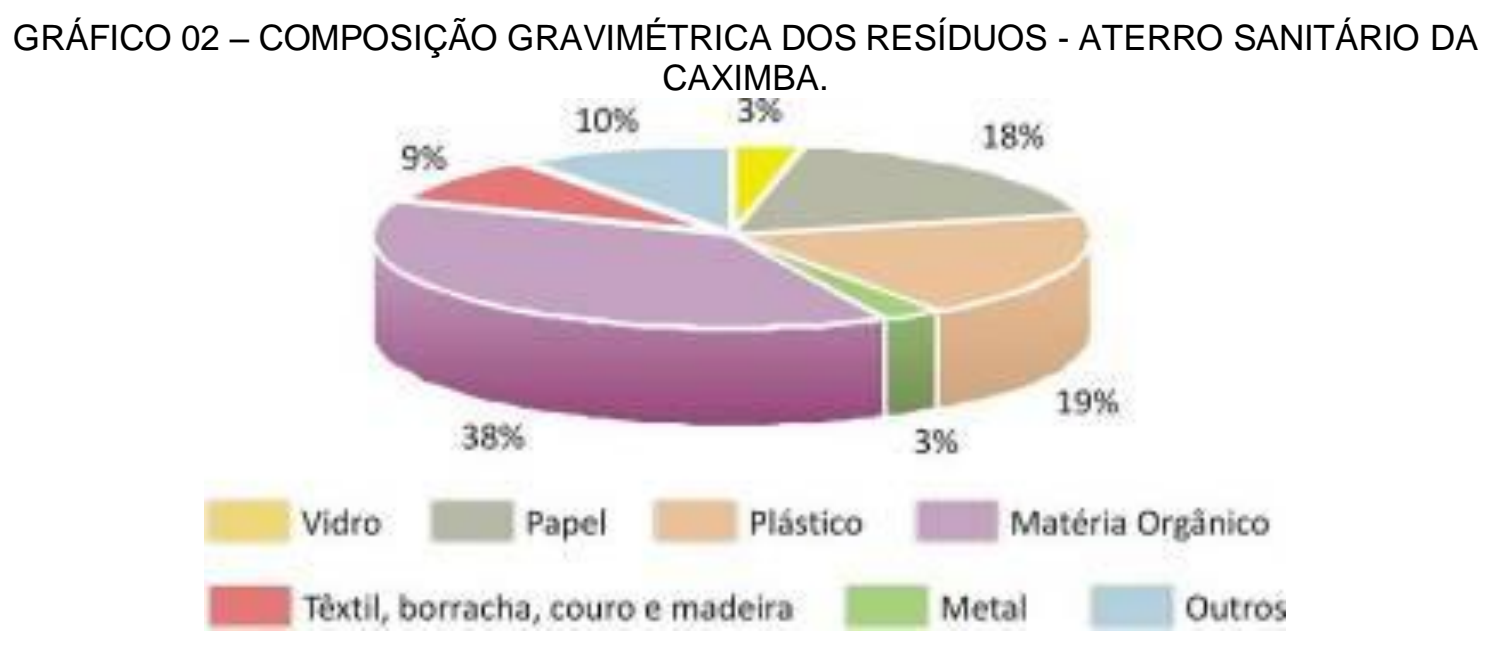

Fonte: Autor, baseado em CONRESOL (2007)

Se analisada a espacialização dos resíduos coletados, de modo geral, os municípios com maior porcentagem de população urbana geram maior quantidade de resíduos, salvo pequenas particularidades referentes a outros fatores que influenciam a geração dos resíduos, tais como nível sócio-econômico da população e atividade econômica predominante. Como pode ser observado na tabela abaixo Curitiba se destaca, contribuindo com $72 \%$ de todo o resíduo gerado no Recorte de Análise.

Sobre o Sistema Atual vale ainda ressaltar as duas Estações de Transbordo existentes, localizados nos municípios de Colombo e Campo Largo, com capacidade de 20 e 80 toneladas, respectivamente. 
QUADRO 04 - QUANTIDADE DE RESÍDUOS GERADOS, POPULAÇÃO URBANA E GRAU DE URBANIZAÇÃO

\begin{tabular}{|lrrrr|}
\hline Município & $\begin{array}{c}\text { Quantidade } \\
\text { (ton / ano) }\end{array}$ & $\begin{array}{c}\text { População } \\
\text { Urbana }\end{array}$ & $\begin{array}{c}\text { Grau de } \\
\text { Urbanização }\end{array}$ & $\begin{array}{c}\text { Geração per capita } \\
\text { (kg/hab/dia) }\end{array}$ \\
Curitiba & 432.972 & 1.797 .408 & 100,00 & 0,803 \\
São José dos Pinhais & 50.541 & 263.622 & 89,7 & 0,639 \\
Colombo & 28.938 & 233.916 & 95,4 & 0,412 \\
Pinhais & 20.112 & 112.195 & 97,8 & 0,598 \\
Araucária & 16.784 & 111.952 & 91,4 & 0,500 \\
Campo Largo & 15.028 & 97.824 & 83,2 & 0,512 \\
Almirante Tamandaré & 12.221 & 93.060 & 96,0 & 0,438 \\
Fazenda Rio Grande & 9.762 & 75.006 & 94,1 & 0,434 \\
Campina Grande do Sul & 4.003 & 35.269 & 75,1 & 0,378 \\
Campo Magro & 2.713 & 22.443 & 12,3 & 0,403 \\
Quatro Barras & 2.361 & 18.133 & 89,8 & 0,434 \\
Mandirituba & 1.927 & 20.408 & 35,7 & 0,315 \\
Contenda & 1.310 & 14.800 & 47,7 & 0,295 \\
Bocaiúva do Sul & 1278 & 9.533 & 39,4 & 0,447 \\
Balsa Nova & 970 & 10.636 & 31,4 & 0,302 \\
Quitandinha & 600 & 15.901 & 19,9 & 0,126 \\
Piraquara & (sem dado) & 33.829 & 46,4 & (sem dado) \\
\hline
\end{tabular}

Fonte:CONRESOL, 2007 / Leituras Regionais - IPARDES.

Sua existência se justifica pela distância a ser percorrida pelos veículos coletores. Segundo JARDIM (2000), além do aumento do custo de transporte, as grandes distâncias ocasionam uma diminuição da produtividade dos veículos, em função do tempo ocioso gasto para descarga e retorno ao setor de coleta.

Para estas situações se recomenda a utilização de Estações de Transferência ou Transbordo que reduzem o percurso dos veículos coletores, gerando maior economia e permitindo o transporte de resíduos para seu destino final em caminhões de grande capacidade e menor custo. O mapa a seguir espacializa esta situação, localizando os pontos fundamentais do sistema e os fluxos realizados. 


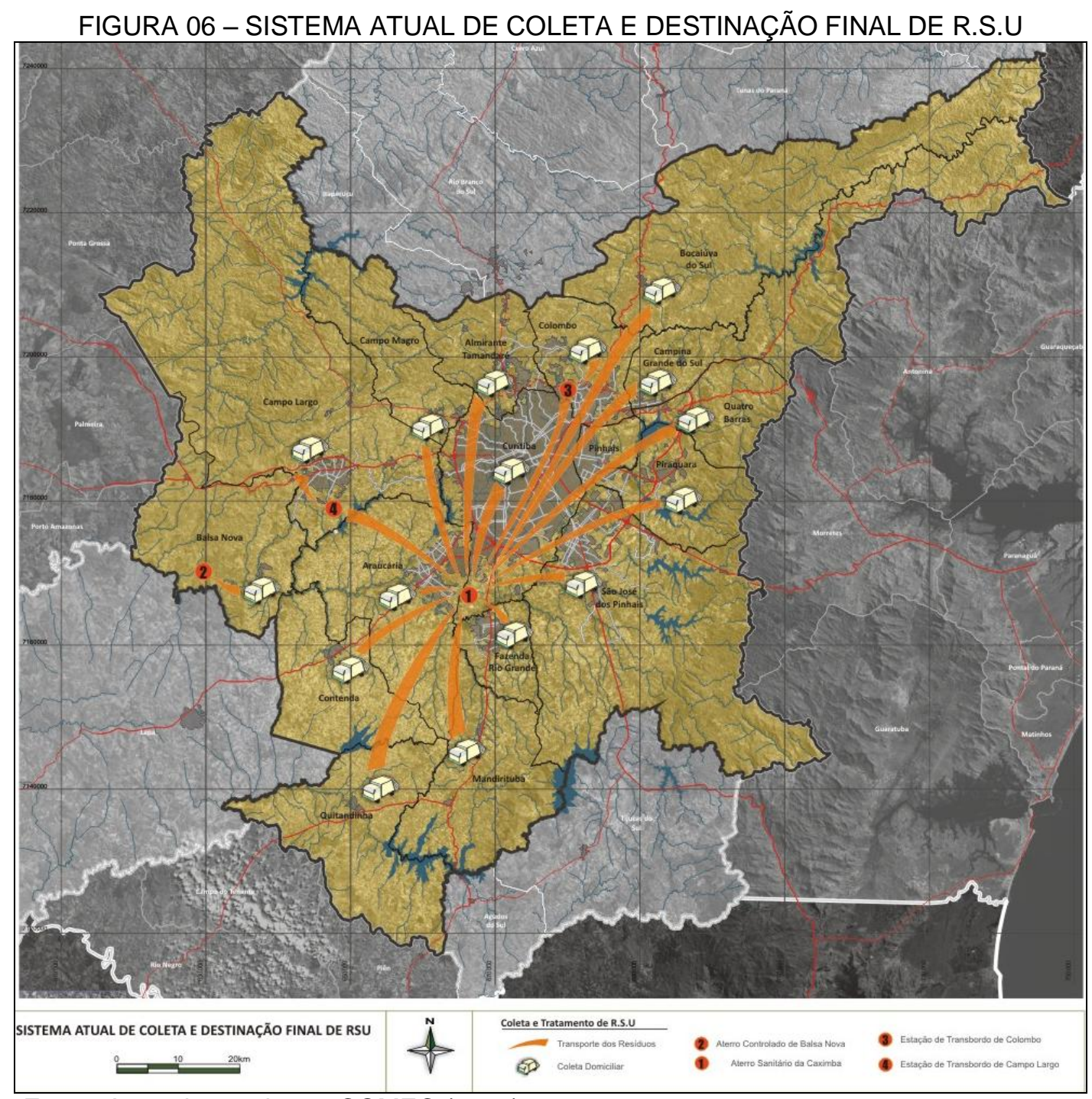

Fonte: Autor, baseado em COMEC (2000)

\section{POLÍTICA REGIONAL DE COMPOSTAGEM}

A Política Regional de Compostagem tem por objetivo apontar diretrizes territoriais e projetuais, através das quais seja viabilizada a prática da compostagem dos resíduos orgânicos na Área de Intervenção.

O Recorte de Análise apresenta como característica particular a presença de duas áreas, claramente contrastantes. A primeira compreende a mancha urbana contínua, abrangendo Curitiba e as porções urbanizadas dos municípios vizinhos. Esta área reúne mais de $90 \%$ da população do recorte de planejamento, concentrando a maior parte dos resíduos gerados. Apresenta infra-estrutura viária 
satisfatória, além de não possuir grandes porções inseridas em Área de Proteção de Manancial.

A segunda área é predominantemente rural, onde são verificadas aglomerações urbanas de pequeno porte, tendo por vocação o Apoio Rural. Nesta unidade a população encontra-se dispersa e a mobilidade viária é prejudicada pela qualidade das rodovias municipais. Ainda se destaca por apresentar grande porcentagem de seu território inserido em Área de Manancial.

Partindo deste panorama, propõe-se a divisão da Área de Intervenção em duas Unidades de Planejamento (UP), onde as diretrizes e tipologias projetuais se diferenciam, visando se adequar às especificidades de cada UP. Deste modo, para efeito da proposta o primeiro compartimento será denominado Unidade de Planejamento Urbana (correspondente ao NUC definido pela COMEC) e o segundo Unidade de Planejamento Rural (figura 07).

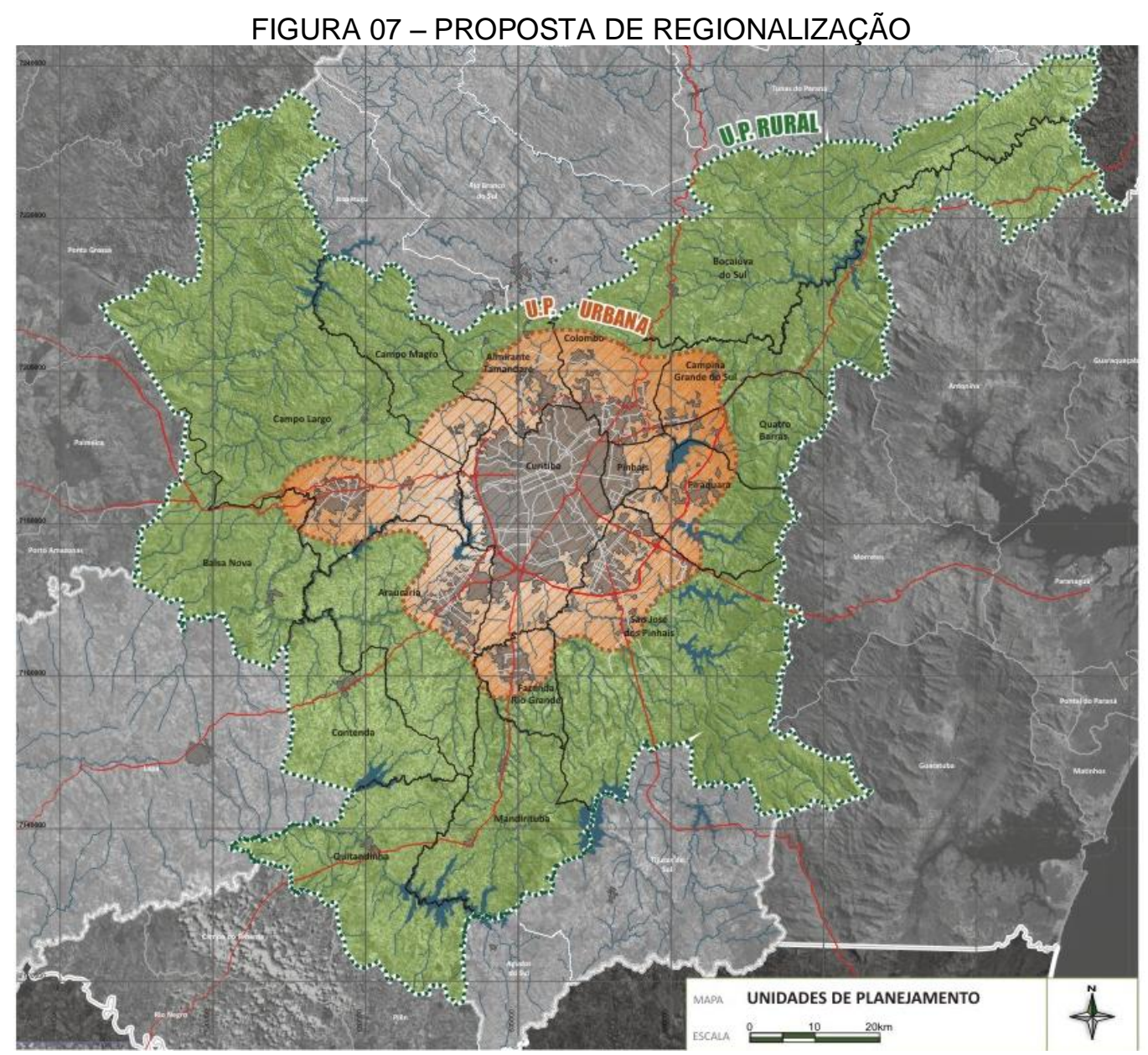

Fonte: Autor. 
Como pode ser visualizado na Figura 08, para cada uma das Unidades de Planejamento é proposto um Sistema de Compostagem diferenciado, de forma a se adequar aos diferentes contextos supracitados.

As principais diretrizes definidas para cada UP relacionam mecanismo de funcionamento e sustentabilidade financeira. Para efeito deste artigo, optou-se por detalhar a proposta da Unidade de Planejamento Urbana, onde se propõe a implantação de Usinas de Triagem e Compostagem (UTC) de grande porte, processando em média 1000 t/dia, sendo também necessário definir um novo sítio para o Aterro Sanitário.

Tais instalações serão dispostas em locais estratégicos, de modo a conciliar viabilidade econômica e preservação dos recursos naturais, em complexos que além de produzir o composto orgânico atuarão como locais de educação ambiental. Sua implantação e administração serão de responsabilidade do CONRESOL, que arcará com os investimentos necessários para sua execução.

FIGURA 08 - SISTEMA REGIONAL DE COMPOSTAGEM

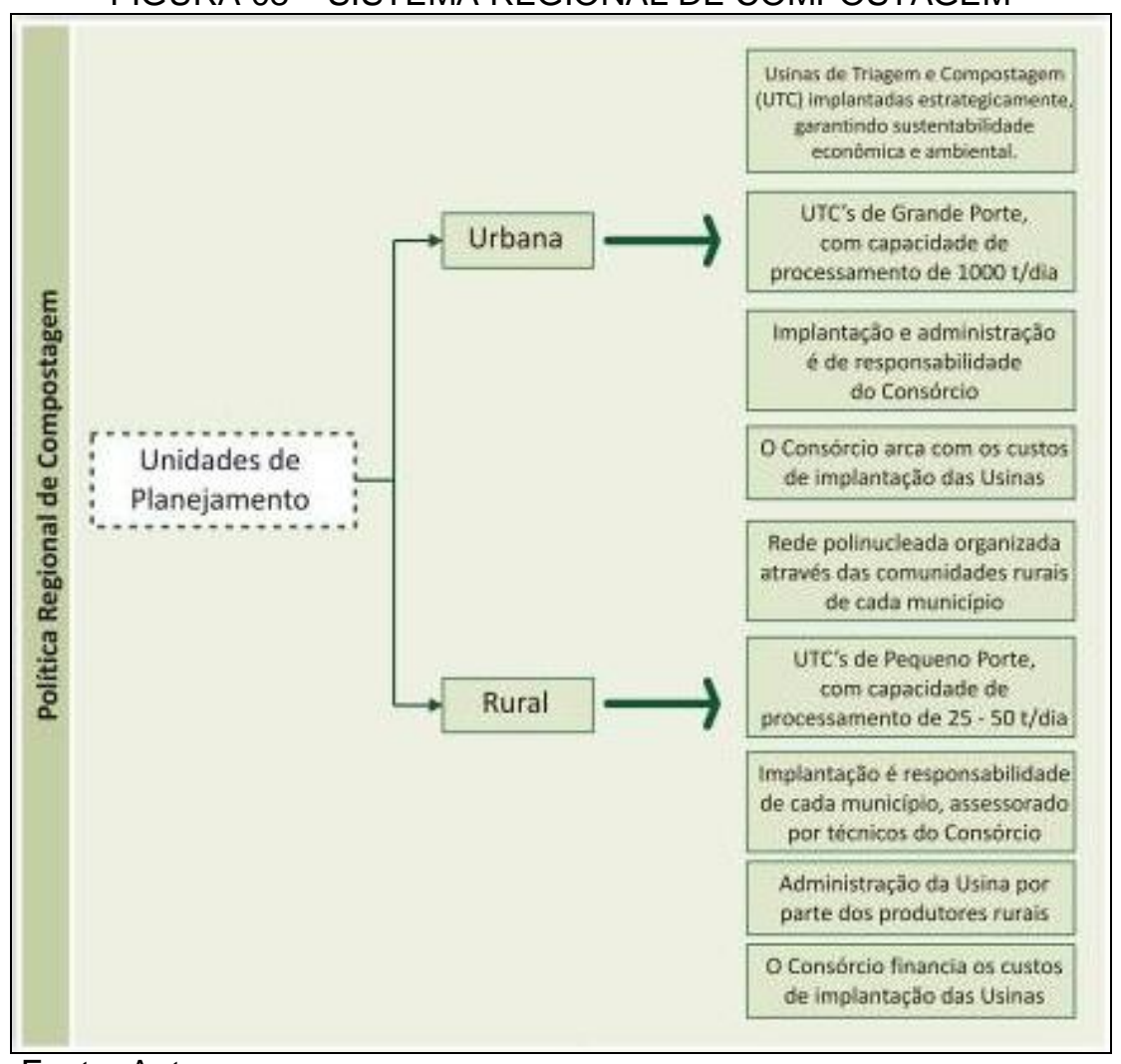

Fonte: Autor. 
Para correta definição dos lugares mais adequados, optou-se pela realização do mapeamento das Aptidões e Restrições da Área de Intervenção. Estes dados, conciliados com a macro-leitura exposta anteriormente, fornecem subsídios para a construção do Cenário Tendencial, que aponta o prognóstico caso nada seja alterado.

De modo a obter um panorama geral das restrições do território, foram considerados os aspectos técnicos de maior relevância apontados por LIMA (1999), quais sejam: Mananciais de Abastecimento de Água; Geologia e Pedologia (sobretudo planícies aluviais e gleissolos); Unidades de Conservação, declividades superiores a $45^{\circ}$ e Remanescentes de Mata Nativa; Acessibilidade Viária e Áreas Urbanas (com um raio de proteção de $1 \mathrm{~km}$ das mesmas).

Após esta etapa, formulou-se então o Cenário Desejado, onde a partir da leitura do panorama atual propõe-se o novo Sistema de Gestão dos Resíduos Sólidos na Unidade de Planejamento Urbana. Para a construção dos cenários, tomou-se como horizonte de planejamento o prazo de 10 anos. Com a projeção da população para 2018, foi considerado o valor de geração de lixo per capita atual, como forma de apontar um prognóstico pessimista (visto que a tendência mundial aponta para a adoção de práticas de redução). Obteve-se assim, um volume gerado de 2.407 ton/ dia na UP urbana, conforme quadro 05.

\section{Cenário Tendencial}

Com o esgotamento da estrutura atual de tratamento dos R.S.U. na Área de Intervenção, é necessário o levantamento das áreas mais aptas à instalação da nova estrutura. Através das declarações dos responsáveis pelo processo, é possível afirmar que o futuro sistema busca inicialmente substituir o antigo, não sendo vislumbrada uma opção viável de tratamentos dos resíduos orgânicos, sendo os mesmos simplesmente dispostos no Aterro. 
QUADRO 05 - PROJEÇÃO DA POPULAÇÃO PARA 2018

\begin{tabular}{|lrrrr|}
\hline \multicolumn{1}{c}{ Município } & $\begin{array}{r}\text { População } \\
\text { Urbana (2018) }\end{array}$ & $\begin{array}{c}\text { Geração per capita } \\
\text { (kg/hab/dia) }^{\mathbf{2}}\end{array}$ & $\begin{array}{r}\text { Volume de RSU } \\
\text { gerado (kg/dia) }^{\mathbf{3}}\end{array}$ & $\begin{array}{c}\text { \% do Recorte } \\
\text { de Análise }\end{array}$ \\
Curitiba & 1.955 .437 & 0,803 & $1.570 .215,91$ & $65,23 \%$ \\
São José dos & 357.651 & 0,639 & $228.538,99$ & $9,49 \%$ \\
Pinhais & 333.498 & 0,412 & $137.401,18$ & $5,71 \%$ \\
Colombo & 147.773 & 0,598 & $88.368,25$ & $3,67 \%$ \\
Pinhais & 170.909 & 0,5 & $85.454,50$ & $3,55 \%$ \\
Araucária & 177.854 & 0,438 & $77.900,05$ & $3,24 \%$ \\
Alm. Tamandaré & 172.029 & 0,434 & $74.660,59$ & $3,10 \%$ \\
Fazenda Rio & 113.430 & 0,512 & $58.076,16$ & $2,41 \%$ \\
Grande & 106.027 & 0,386 & $40.926,42$ & $1,70 \%$ \\
Campo Largo & 70.807 & 0,378 & $26.765,05$ & $1,11 \%$ \\
Piraquara & 46.974 & 0,403 & $18.930,52$ & $0,79 \%$ \\
Campina G. do Sul & $\mathbf{3 . 6 5 2 . 3 8 9}$ & & $\mathbf{2 . 4 0 7 . 2 3 7 , 6 2}$ & $\mathbf{1 0 0 , 0 0 \%}$ \\
Campo Magro & - & &
\end{tabular}

${ }^{1}$ Segundo projeção realizada por COMEC (2006) / 2 Geração atual segundo CONRESOL (2007), ${ }^{3}$ Obtido através da multiplicação da População pela Geração per capita.

Fonte: Autor.

Tal prática tem como conseqüência o aumento de 918 toneladas aterradas por dia, ou $1300 \mathrm{~m}^{3}$ por dia $^{4}$. Isto levaria ao aumento da área necessária de implantação do aterro, dificultando a localização de um sítio próximo às áreas de coleta, reduzindo a eficiência econômica do processo.

Ressaltam-se ainda os vetores de crescimento $^{5}$, que apontam a expansão urbana ocorrendo no sentindo de Colombo, Araucária, Fazenda Rio Grande e S. José dos Pinhais. Neste sentido, é fundamental a preservação das Áreas de Manancial, que circundam a maior parte da mancha urbana da Área de Intervenção, de modo a garantir o abastecimento de água na região. Vale ainda destacar o Aqüífero Karst, que além de constituir reserva estratégica de água para a Região Metropolitana de Curitiba, apresenta condições altamente instáveis, com risco de colapsos e afundamentos. Ainda apresenta alta vulnerabilidade à contaminação das águas subterrâneas. Sendo assim, a localização de qualquer atividade referente aos resíduos sólidos sob esta área deve ser descartada.

\footnotetext{
${ }^{4}$ Considerando o valor médio de $700 \mathrm{~kg} / \mathrm{m}^{3}$ de lixo

${ }^{5}$ Segundo leitura da dinâmica metropolitana realizado pela COMEC no PDI- 2006.
} 


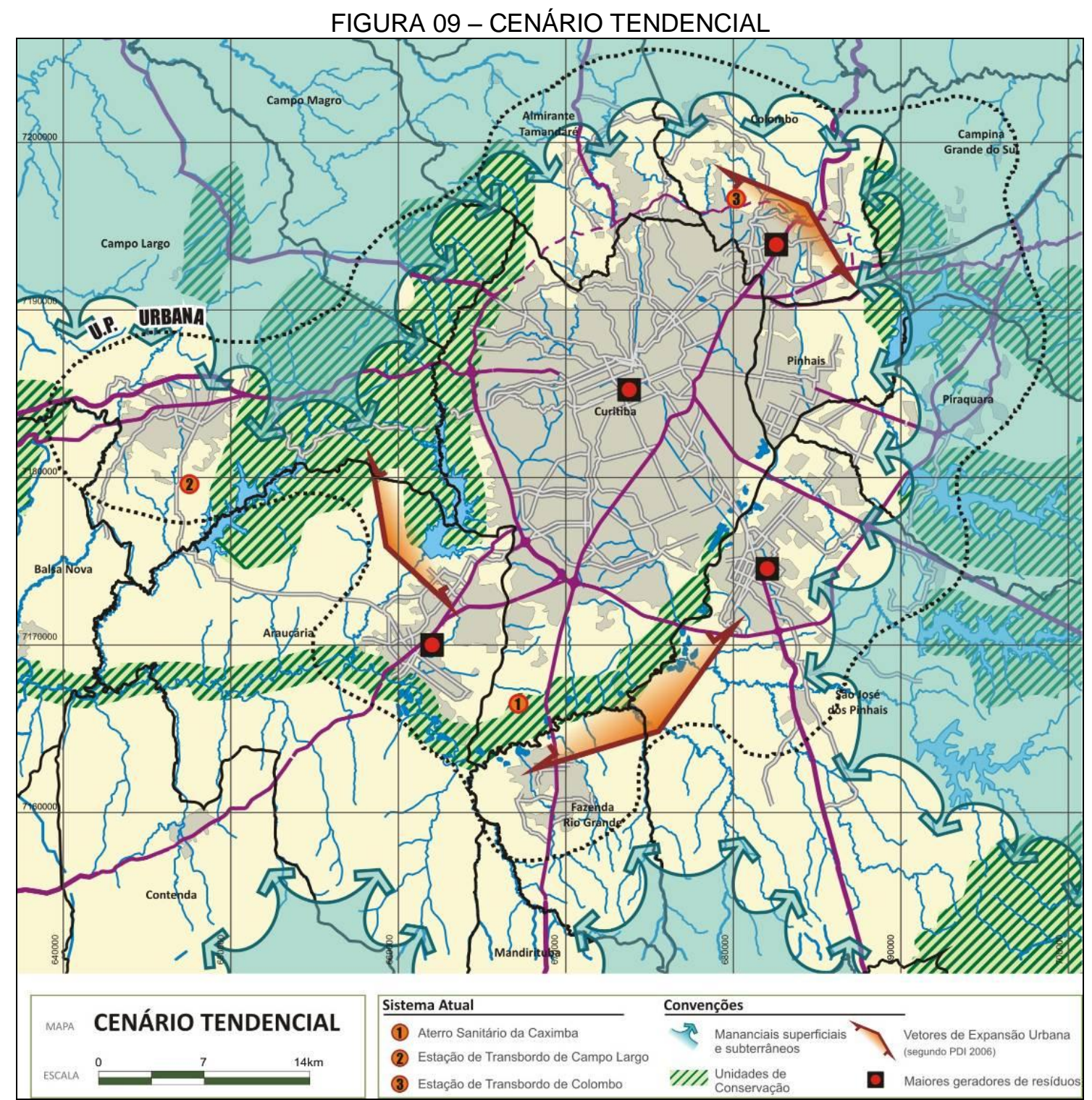

Fonte: Autor.

\section{Cenário Proposto}

O Cenário Proposto tem como base o Planejamento Estratégico, procurando não só suprir as necessidades do Sistema, mas também agir de modo a potencializar os pontos positivos e oportunidades identificadas na Área de Intervenção. Deste modo, através do potencial existente nos resíduos orgânicos coletados propõe-se o seu processamento em Usinas de Triagem e Compostagem (UTC), tendo como resultado um fertilizante orgânico, que ao ser vendido no mercado metropolitano, reforça a viabilidade do empreendimento. Dentro de uma 
estimativa básica, o processamento das 918 toneladas de resíduos orgânicos geraria uma fonte de renda da ordem de $R \$ 275.000,00$ por dia $^{6}$.

Devido as grandes proporções territoriais existentes na U.P. Urbana, recorrese a ROGERS (2001), que defende a organização polinuclear, ao invés da centralização dos processos em um único pólo. Tais núcleos, devidamente interligados, geram a maximização da eficiência energética, reduzindo custos e fluxos de transporte e conseqüentemente a emissão de poluentes no meio ambiente.

Dentro desta concepção de planejamento, propõe-se o estabelecimento de dois Sistema de Compostagem: Sistema Norte e Sistema Sul, com processamento médio de 1200 ton/dia cada.

Para a localização das duas UTC's, partiu-se das áreas aptas, excluindo aquelas que estavam inseridas em regiões de expansão urbana. Dentro destas opções, foram selecionadas duas áreas que repartissem igualmente a unidade de planejamento, reduzindo as distâncias de transporte. Os locais das usinas podem ser vistos na espacialização na Figura 10.

A divisão dos municípios segundo os dois sistemas propostos se deu basicamente pelos critérios de proximidade espacial e volume de resíduos gerados, de modo a equilibrar o processamento entre as duas Usinas. Deste modo, Curitiba foi repartida em duas, balanceando sua contribuição em cada sistema.

Quanto ao Aterro, optou-se por concentrar todas as atividades em apenas uma área, visto o impacto ambiental deste tipo de empreendimento e os custos de instalação. Deste modo, o novo Aterro Sanitário se localiza junto à Usina de Triagem e Compostagem Sul, no município de Fazenda Rio Grande. Os rejeitos não reaproveitáveis originados na UTC Norte serão transportados para a UTC Sul através de caminhões de fundo móvel, que apresentam menor custo por km rodado devido à sua grande capacidade.

Em ambas as Usinas serão processados os resíduos provenientes da coleta convencional. $\mathrm{O}$ destino da coleta seletiva continuará sendo aquela dada por cada município integrante do Consórcio. Contudo, a coleta seletiva é responsável pela

\footnotetext{
${ }^{6}$ Tendo em vista um composto orgânico de qualidade, com preço de mercado de $\mathrm{R} \$ 300,00 /$ ton
} 
segregação de apenas $20 \%$ de todo o resíduo reciclável contido no lixo doméstico. Deste modo, além da produção do composto orgânico, as UTC's serão responsáveis pela segregação de 380 ton/dia de recicláveis cada.

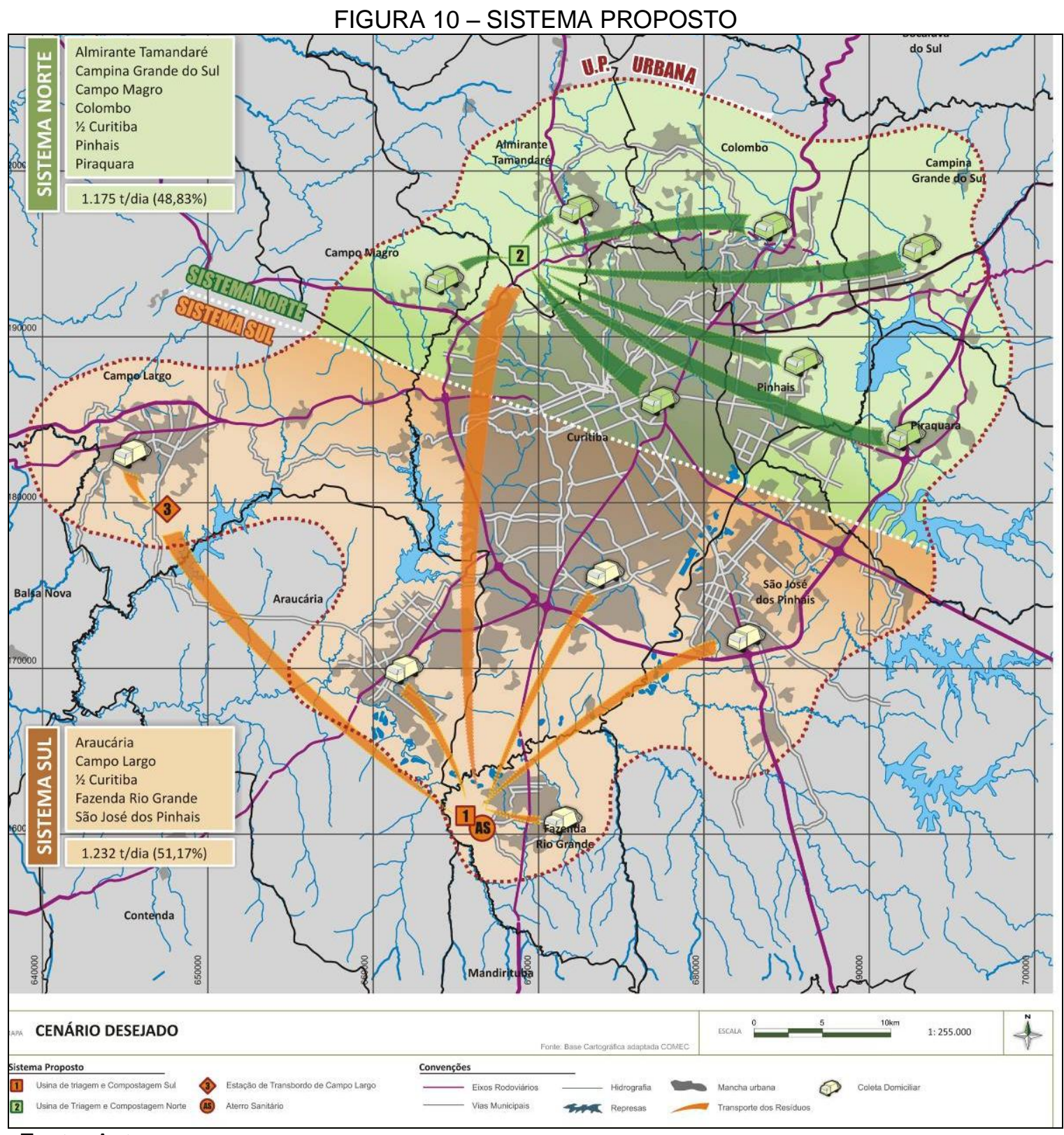

Fonte: Autor. 


\section{CONCLUSÕES}

A gestão dos resíduos sólidos urbanos é um dos impasses ambientais de maior gravidade na sociedade moderna. A pressão exercida pelo contínuo despejo somada a problemática da destinação final vem aumentando ainda mais a complexidade das soluções de manejo de resíduos.

Dentro deste panorama, a Região Metropolitana de Curitiba vêm desenvolvendo uma postura adequada ao seu território, com a proposta de adoção de um modelo diferenciado de tratamento dos resíduos, onde serão adotadas progressivamente novas tecnologias de modo que, no prazo de seis anos, apenas $15 \%$ dos resíduos sejam destinados ao aterro sanitário.

Duas grandes questões emergem neste cenário, quais sejam: a definição da tecnologia de Processamento dos Resíduos e a forma pela qual este sistema se insere dentro do espaço da RMC. Frente a estas questões, apresentou-se uma proposta de ordenamento espacial do sistema, definindo macro-diretrizes de duas unidades de planejamento, urbana e rural, dando ênfase na primeira pelo grau de complexidade e conurbação do território metropolitano de Curitiba.

Embora a adoção de adequadas soluções tecnológicas seja fundamental, a problemática dos resíduos sólidos urbanos não esta somente na solução de sistemas e tecnologias, mas se estende ao âmbito político, de modo que o desafio esteja também na alteração do sistema de valores da sociedade, compatibilizando-o com as exigências de sustentabilidade socioambientais. 


\section{REFERÊNCIAS}

Coordenação da Região Metropolitana de Curitiba. Plano de Desenvolvimento Integrado da Região Metropolitana de Curitiba - 2006. COMEC: Curitiba, 2006

Coordenação da Região Metropolitana de Curitiba. Programa de Saneamento Ambiental da Região Metropolitana de Curitiba - PROSAM. COMEC: Curitiba, 2000.

Consórcio Intermunicipal para Gestão de Resíduos Sólidos Urbanos (CONRESOL). Plano de Gerenciamento do Tratamento e Destinação de R.S.U. SMMA: Curitiba: 2007.

Instituto Brasileiro de Geografia e Estatística. Pesquisa Nacional de Saneamento Básico. PNSB, 2000. Disponível em: <http://www.ibge.gov.br > Acesso em 15 de Outubro de 2008.

Instituto Paranaense de Desenvolvimento Econômico e Social. Leituras Regionais: Mesorregião metropolitana de Curitiba. Curitiba, IPARDES, 2004.

IPARDES, Referências Ambientais e Socioeconômicas para o Uso do Território do Paraná. IPARDES, 2006. Disponível em: <http://www.ipardes. gov.br/webisis.docs/zee_2006.pdf > Acesso em 12 de Novembro de 2008.

JARDIM, Nilza Silva (org.) Lixo Municipal: Manual de Gerenciamento Integrado. $2^{\underline{a}}$ ed. São Paulo: IPT / CEMPRE, 2000.

LIMA, G. S. Seleção de áreas para implantação de aterros sanitários: uma proposta baseada na Análise do Valor e Lógica Fuzzy. Dissertação de Mestrado, COPPE/Universidade Federal do Rio de Janeiro, 1999.

MENEZES, M.G. Lixo, Cidadania e Ensino. São Paulo: Sociedade Brasileira de Química, 2005.

MOURA, Rosa. Como Andam as Metrópoles: RMC. Curitiba: Ipardes, 2006

OLIVEIRA, Gilberto de. Consórcio Intermunicipal para o manejo integrado de lixo em cinco municípios da região administrativa de Bauru. Dissertação de Mestrado. Universidade Estadual Paulista. São Paulo, 2004.

ROGERS, Richard. Cidades para um Pequeno Planeta. Barcelona: Gustavo Gili, 2001.

(Recebido em março/2009. Aceito em julho/2009) 